\title{
Immunoglobulin G4-Related Disease Manifesting as Isolated, Typical, and Nontypical Gastroesophageal Lesion: A Research of Literature Review
}

\author{
Samiullah Khan Lan-ping Zhu Kui Jiang Wentian Liu Xin Chen \\ Bang-mao Wang \\ Department of Gastroenterology and Hepatology, Tianjin Medical University General Hospital, Tianjin, PR China
}

\section{Keywords \\ Esophageal immunoglobulin G4-related disease · Gastric immunoglobulin G4-related disease · Isolated lesions . \\ Typical lesions · Nontypical lesions}

\begin{abstract}
Background: Immunoglobulin G4-related disease (IgG4-RD) is an autoimmune inflammatory and fibrotic condition. The disease is characterized by tissue infiltration with dense lymphoplasmacytes and IgG4-positive plasma cells. Summary: The aim of this study was to provide gastroenterologists with novel insights into evaluating the gastroesophageal involvement with IgG4-RD or mimickers of this condition and to give special attention to clinicopathological features. A literature review was performed using the PubMed database. A total of 39 studies presenting cases in the form of isolated, typical, and nontypical gastroesophageal involvement with IgG4-RD published between 2010 and 2018 were included. These studies were thoroughly reviewed for symptoms, lesion location, lesion type, lesion size, immune-histopathology, associated diseases, treatment, and follow-up. Of the 39 studies reviewed, 9 were esophageal IgG4-RD lesions, isolated esophageal IgG4-RD 66.66\% (6/9), a typical form of esophageal IgG4-RD $11.11 \%$ (1/9), and nontypical form
\end{abstract}

esophageal IgG4-RD 22.22\% (2/9). The 30 gastric IgG4-RD that include isolated gastric IgG4-RD $46.66 \%$ (14/30), typical gastric lgG4-RD 40\% (12/30), and nontypical gastric lgG4-RD $13.33 \%$ (4/30). The majority of lesions were inflammatory tumors, ulceration, nodular lesions, chronic gastritis, and malignant lesions. Key Messages: IgG4-RD may be manifested by isolated, typical and nontypical forms of gastroesophageal lesions and should be taken into consideration in the differential diagnosis. Corticosteroids may be the sole diagnostic treatment for this condition.

c 2019 S. Karger AG, Basel

\section{Introduction}

Immunoglobulin G4-related disease (IgG4-RD) is an autoimmune systemic disorder that has been defined in various organs. The disease is characterized by chronic inflammatory condition and histologically by tissue infiltration with dense lymphoplasmacytes, and IgG4-positive (IgG4+) plasma cells, variable count of eosinophils, fibrosis (often storiform fibrosis), and obliterative phle-

S.K. and L.Z. contributed equally to this work.

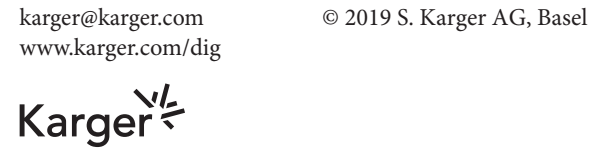


bitis within the lesion area [1-4]. The pathogenesis of IgG4-RD remains unclear; however, type $2 \mathrm{~T}$-helper cells, regulatory $\mathrm{T}$-cell cytokines, and $\mathrm{B}$-cell activating factor have been suggested to be linked with the development of IgG4-RD [5]. IgG4-RD can affect multiple organs simultaneously or can present as a solitary, mass-like lesion [2]. The pancreas "autoimmune pancreatitis" (AIP), hepatobiliary system, retroperitoneum, aorta, kidney, orbit, lungs, lymph nodes, and salivary glands are the most commonly affected organs, although, the manifestation of the upper gastrointestinal tract is relatively rare [2, 6-9].

Many experts of IgG4-RD suspect that reported cases of gastroesophageal IgG4-RD are mimickers of this condition. A recent study on 235 consecutive patients with IgG4-RD revealed that $95 \%$ of patients have at least one of the top 5 manifestations (pancreatitis, sialadenitis, interstitial nephritis, dacryoadenitis, and periaortitis) [10]. In this study, if any one of the above 5 tissues manifestation coexists with gastroesophageal IgG4+ lesions, it may be signaling IgG4-related typical lesions. IgG4+ lesions with no coexistence of any top 5 typical manifestations "pancreatitis, sialadenitis, interstitial nephritis, dacryoadenitis, and periaortitis" or other associated diseases are called IgG4+ isolated or solitary lesions. However, nontypical IgG4-related lesions are referring to the condition other than that of isolated or typical IgG4-RD, such as associated diseases or the presence of concomitant diseases, including Raynoud's disease, Henoch-Schonlein purpura, idiopathic thrombocytopenic purpura, autosomal dominant polycystic kidney disease, and so on.

IgG4-RD and/or the mimickers of this condition are relatively rare in the upper gastrointestinal tract, but are known to occur based on anecdotal case reports. The clinical descriptions of IgG4-related GI disease in these presenting reports range widely and include nodules, tumors, ulceration, wall thickening, gastritis, malignant lesions, vasculitis, fistula, and increases in IgG4+ plasmacytes without obvious morphologic abnormalities.

\section{Materials and Methods}

The literature search was performed using the PubMed database for studies published in English in years 2010-2018. The following combinations of medical headings were used: "esophageal IgG4-RD," "gastric IgG4-RD," "IgG4-related esophageal disease," "IgG4-related gastric disease," "gastrointestinal IgG4-RD," "IgG4related gastroesophageal disease," and "IgG4-related gastrointestinal disease." A total of 39 studies presenting cases of IgG4-RD manifested as isolated, typical, and nontypical gastroesophageal lesions were included in the analysis. These studies were methodically reviewed for symptoms, lesion location, lesion type, lesion size, immune-histopathology, associated or concomitant diseases, treatment, and follow-up. The method for selecting case studies in tables was based on quantitative methods related isolated, typical, and nontypical IgG4+ gastroesophageal lesion discussed in the introduction section.

\section{Results}

The baseline clinical and histopathological characteristics of total 9 cases presenting studies of esophageal IgG4-RD are summarized in Table 1. Dysphagia and weight loss were the 2 most common symptoms in patients with esophageal IgG4-RD lesions. Most patients presented with ulceration and stricture, $6(66.66 \%)$, or mass-like lesions, 2 (22.22\%), mainly involved distal and mid-esophagus, 6 isolated lesions $(66.66 \%), 1$ typical form of a lesion (11.11\%), and 2 nontypical IgG4-related lesions (22.22\%). Elevated serum IgG4+ level observed in 3 patients. Moreover, IgG4+ plasmacytic level was determined in only 3 of the 9 cases; however, all lesions were positive for IgG4 plasmacytes.

Regarding gastric IgG4-RD, 30 cases were studied, the majority of them were submucosal inflammatory tumors 15 (50\%), nodular lesions 4 (13.33\%), ulcerated lesions 7 (23.33\%), chronic gastritis $2(6.66 \%)$, malignant lesions 3 $(10 \%)$, and without data $1(3.33 \%)$.

In isolated gastric IgG4-RD 14 (46.66\%), most lesions were located in the gastric body, presented with gastrointestinal symptoms of abdominal pain, anorexia, nausea, loss of appetite, and anemia. Elevated serum IgG4+ level was unremarkable except in 3 patients $(9,12$, and 13); however, IgG4+ plasmacytic levels were determined in most of cases which is shown in Table 2.

In typical gastric IgG4-RD 12 (40\%), lesions occupied mainly the gastric fundus, body, and antrum with symptoms of abdominal pain, nausea, and vomiting, early satiety, anorexia, weight loss, submandibular salivary glands swelling, decreased visual acuity, renal dysfunction, pruritus, itchy skin lesions, and jaundice. Elevated serum IgG4+ level and increased IgG4+ plasmacytes levels were determined in most of the cases. Moreover, elevated IgG4+/IgG+ ratio was observed in 5 cases $(1,4,7,11$, and $12)$ as well as high IgG level in 4 patients $(1,2,4$, and 5$)$ Table 3.

In nontypical gastric IgG4-RD 4 (13.33\%), lesions were located in the gastric fundus, body, and antrum presented with epigastric pain, fatigue, and anemia due to the bleeding from chronic mucosal ulceration. Interestingly, 


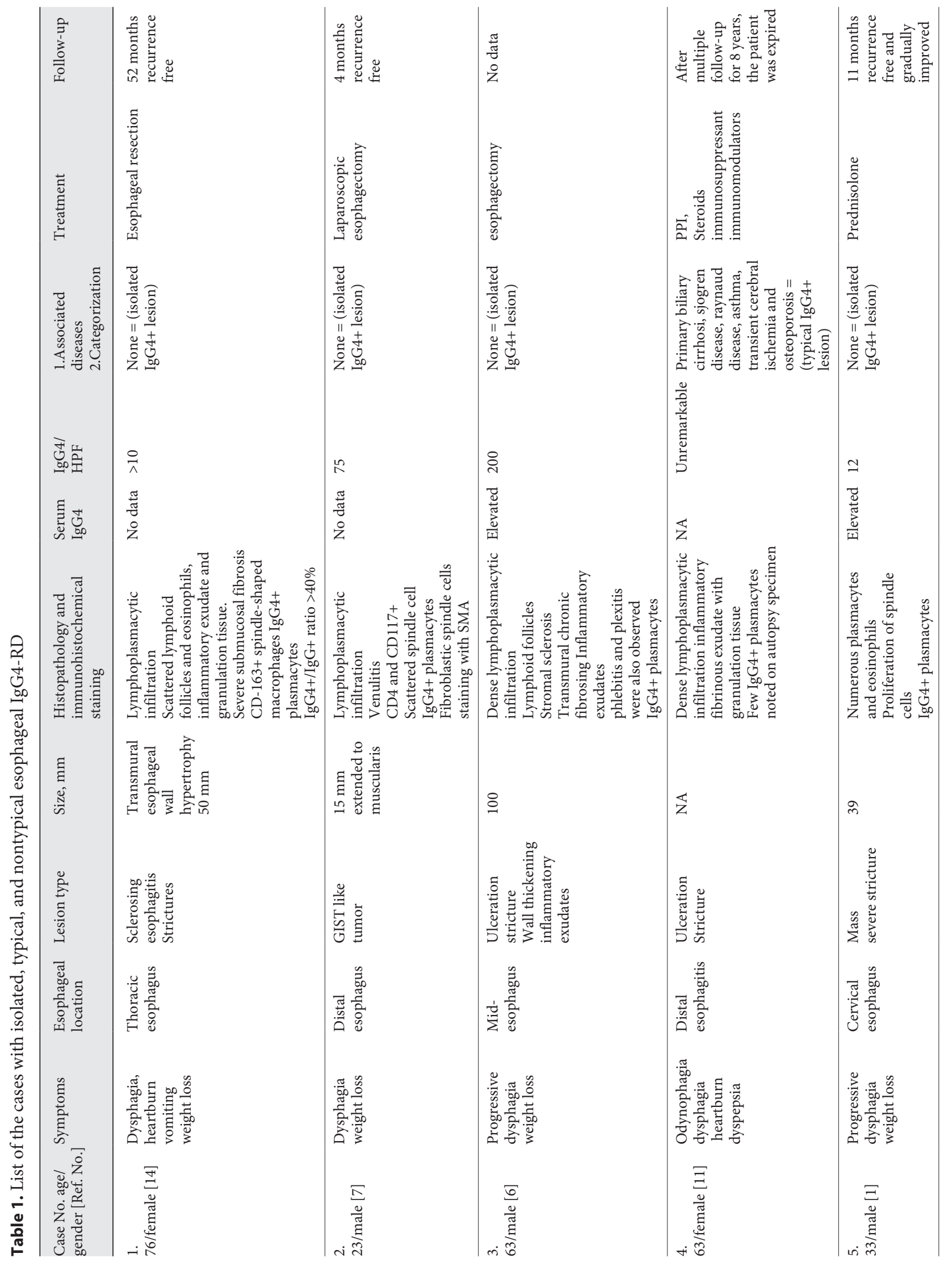




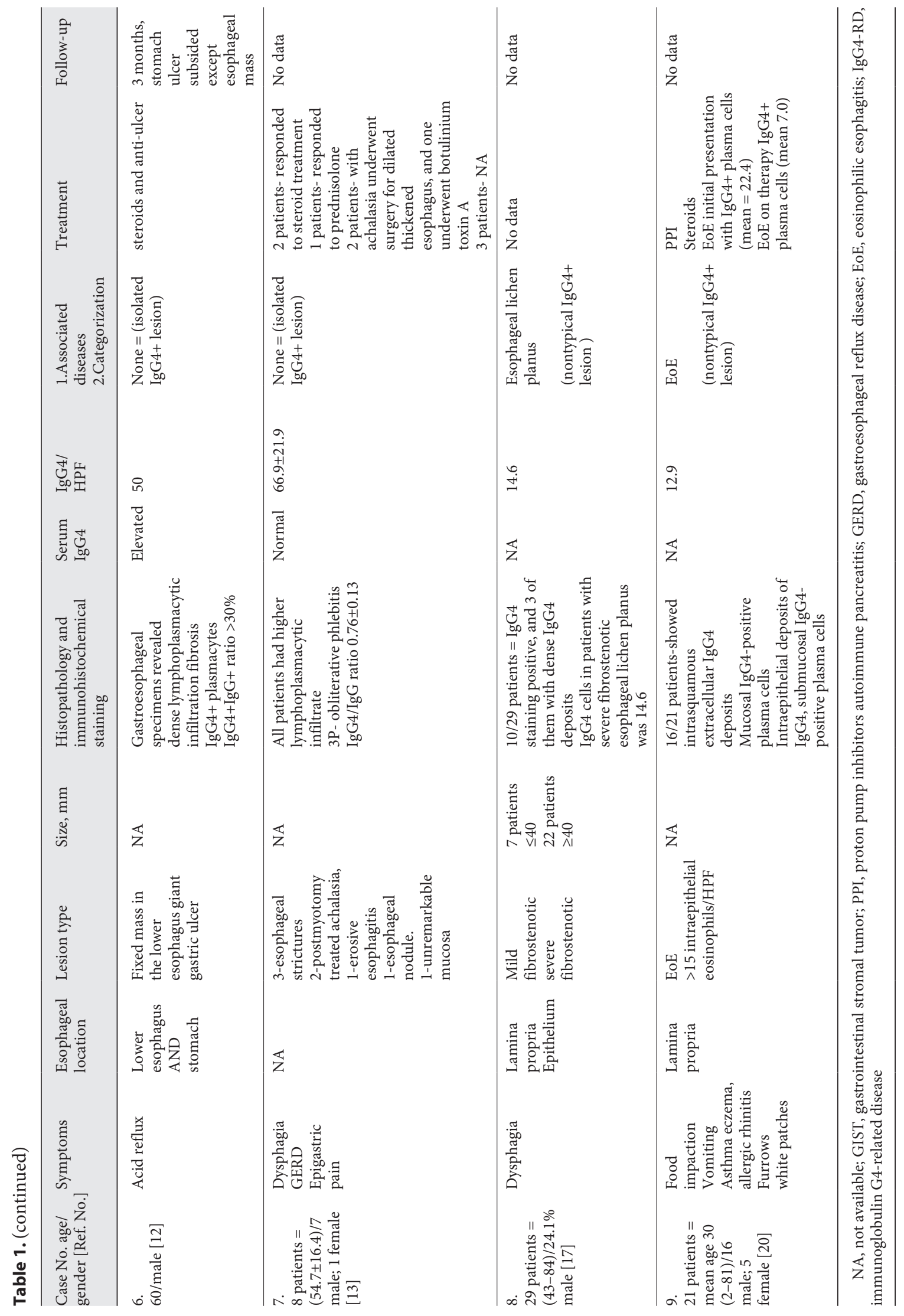




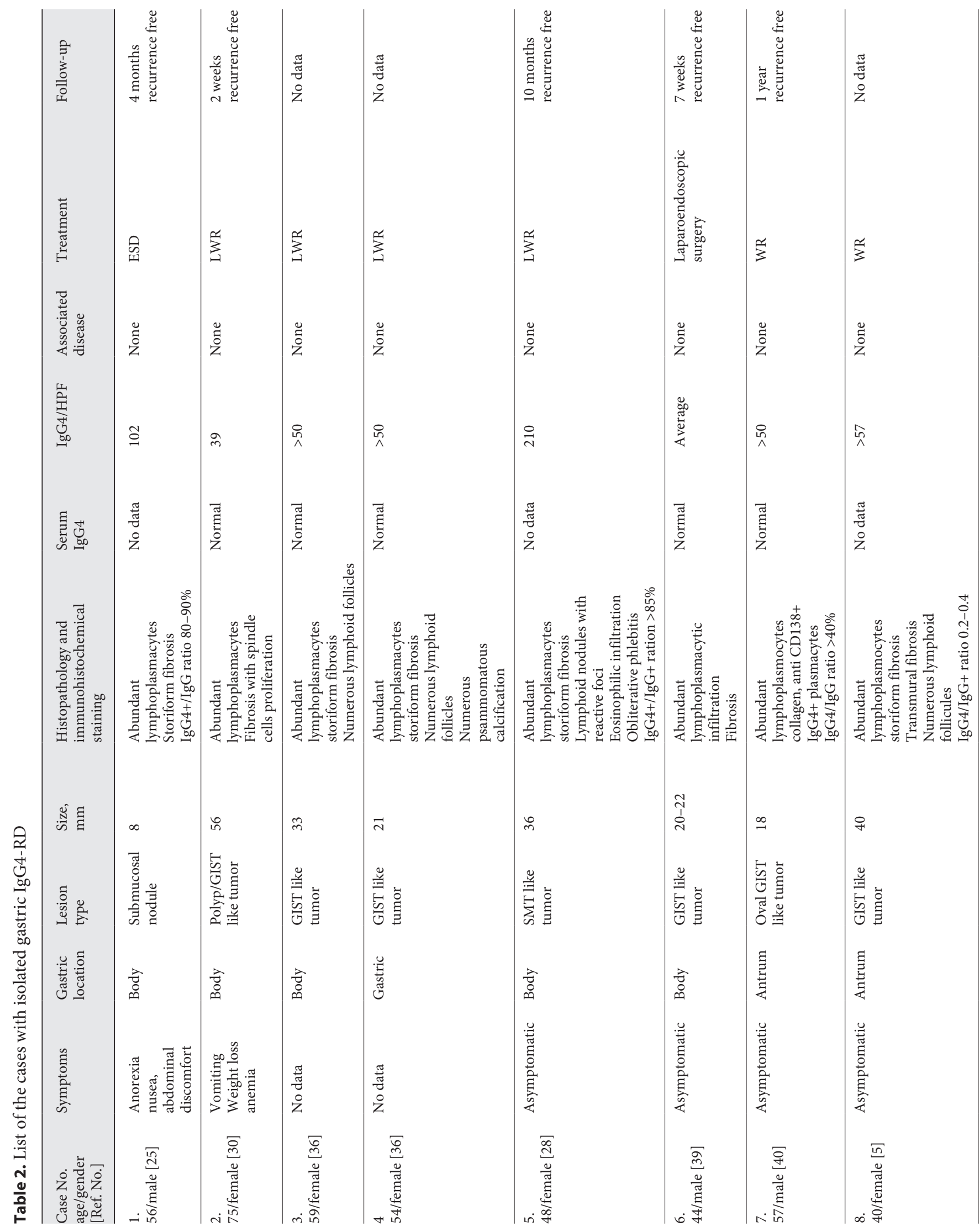




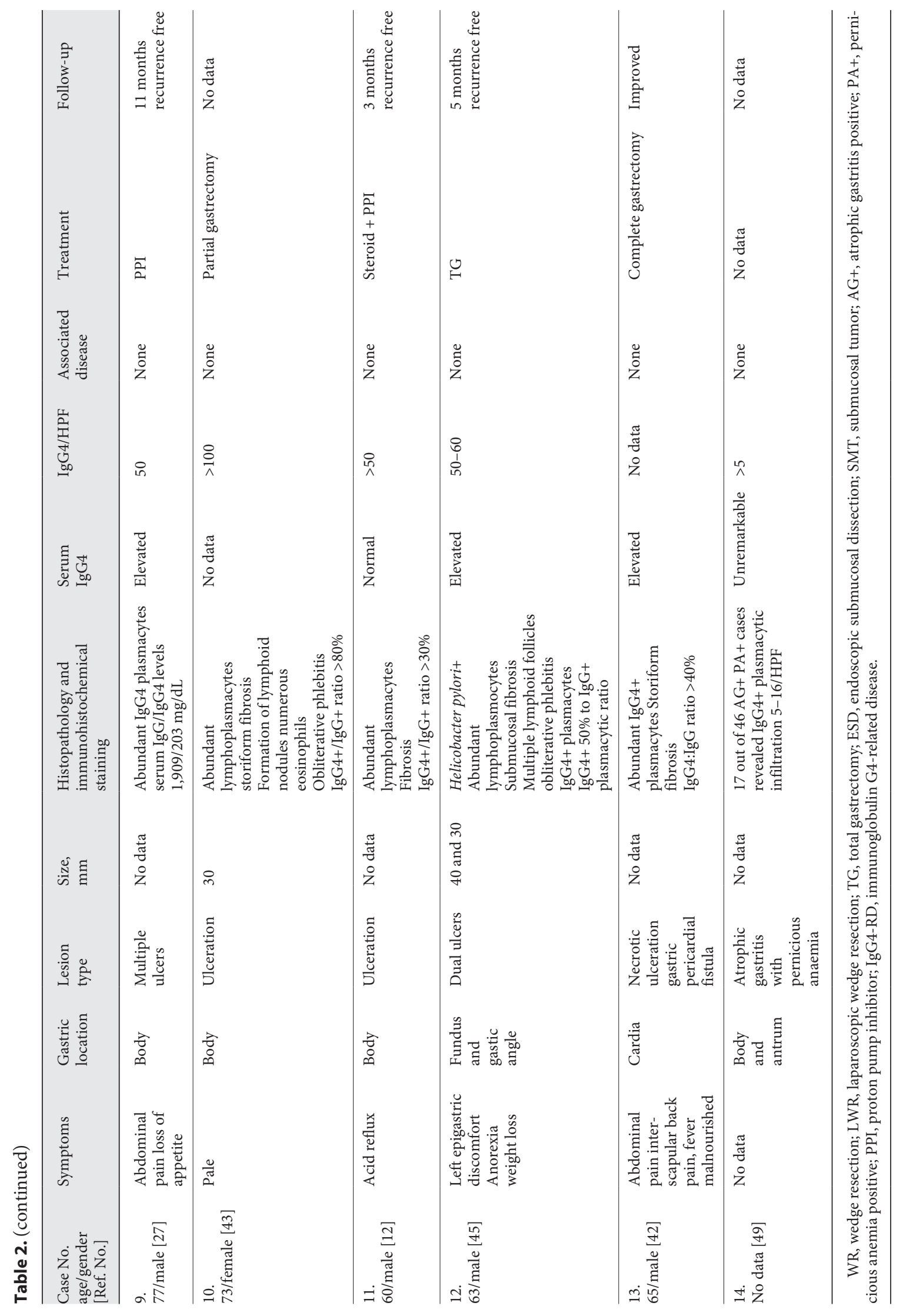




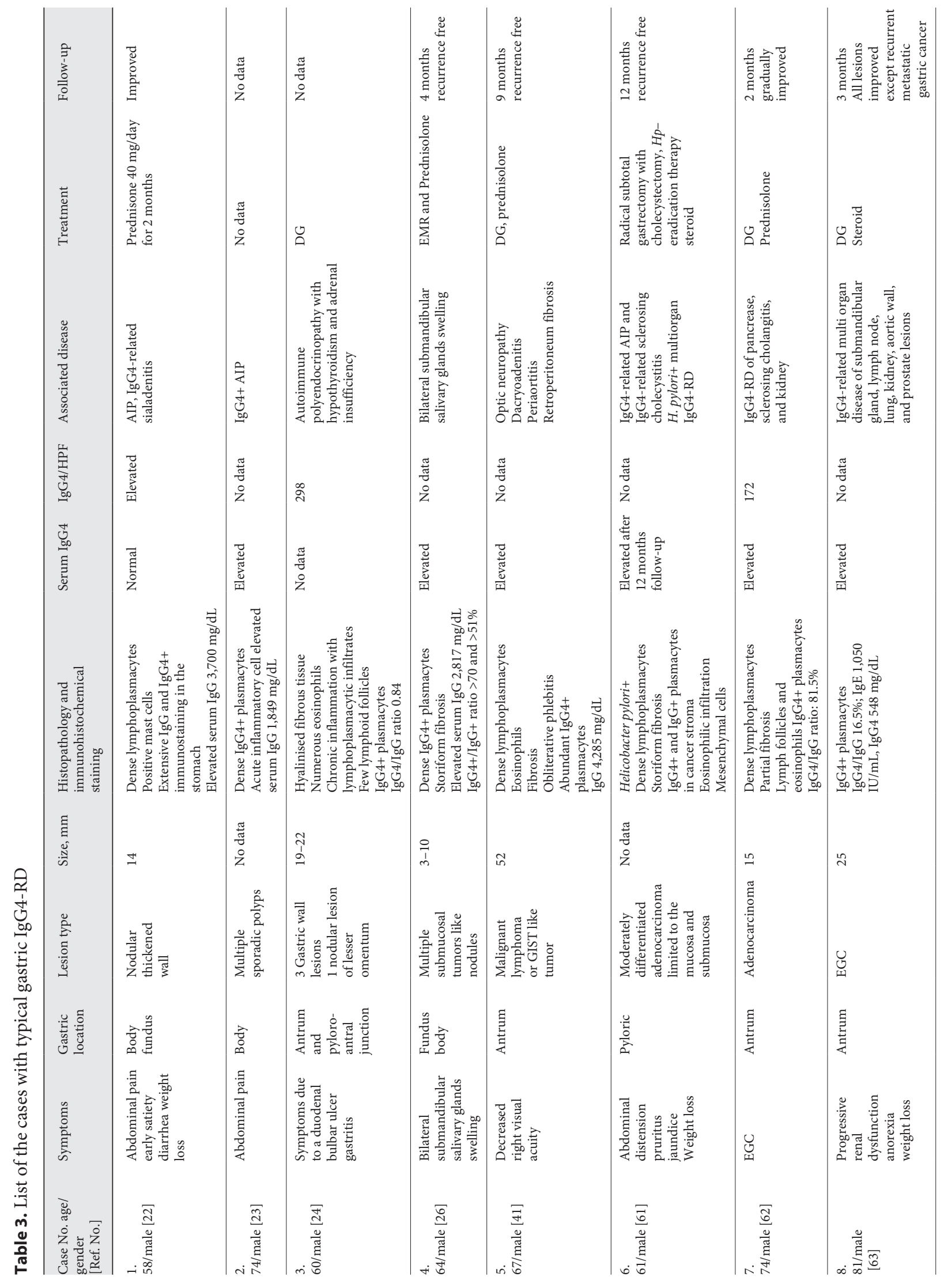




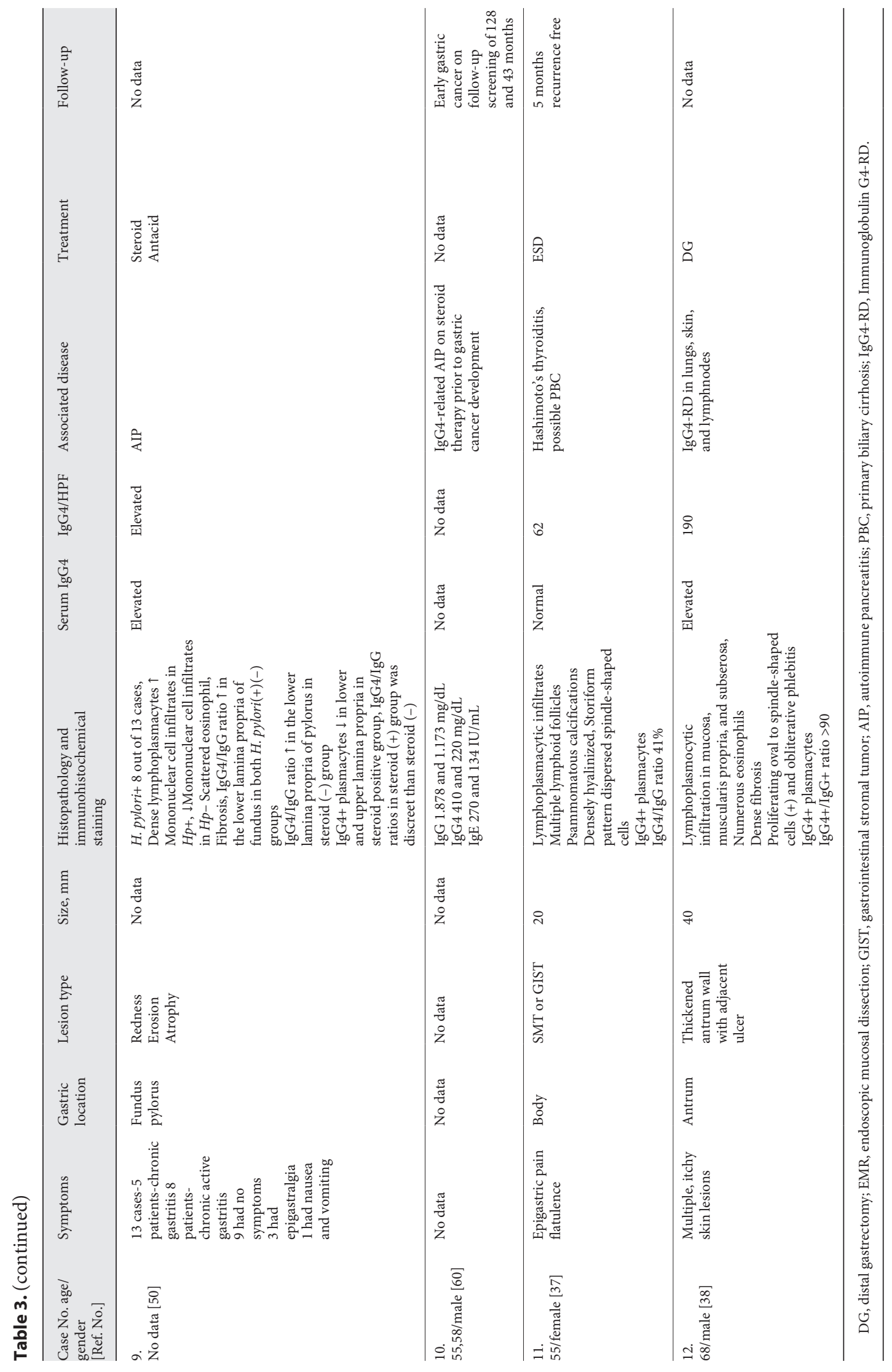


Table 4. List of the cases with nontypical gastric IgG4-RD

\begin{tabular}{|c|c|c|c|c|c|c|c|c|c|c|}
\hline $\begin{array}{l}\text { Case No. } \\
\text { age/gender } \\
\text { [Ref. No.] }\end{array}$ & Symptoms & $\begin{array}{l}\text { Gastric } \\
\text { location }\end{array}$ & Lesion type & Size, $\mathrm{mm}$ & $\begin{array}{l}\text { Histopathology and } \\
\text { immunohistochemical } \\
\text { staining }\end{array}$ & Serum IgG4 & IgG4/HPF & $\begin{array}{l}\text { Associated } \\
\text { disease }\end{array}$ & Treatment & Follow-up \\
\hline $\begin{array}{l}1.45 / \\
\text { female [24] }\end{array}$ & Anemia & Fundus & $\begin{array}{l}\text { Submucosal } \\
\text { nodule } \\
\text { Surface } \\
\text { ulceration }\end{array}$ & 15 & $\begin{array}{l}\text { Dense lymphoplasmacytes } \\
\text { Few lymphoid follicles } \\
\text { Hyalinised fibrous tissue } \\
\text { Numerous eosinophils } \\
\text { Chronic inflammation } \\
\text { IgG4+ plasmacytes } \\
\text { IgG4/IgG ratio } 0.78\end{array}$ & Normal & 363 & $\begin{array}{l}\text { Raynoud's } \\
\text { disease }\end{array}$ & WR & $\begin{array}{l}\text { 6-months } \\
\text { recurrence free }\end{array}$ \\
\hline $\begin{array}{l}\text { 2. 62/ } \\
\text { female [35] }\end{array}$ & $\begin{array}{l}\text { Fatigue } \\
\text { Anermia }\end{array}$ & Antrum & $\begin{array}{l}\text { Ulcerated } \\
\text { tumor }\end{array}$ & $80 \times 30$ & $\begin{array}{l}\text { Dense lymphoplasmocytes } \\
\text { Storiform fibrosis } \\
\text { Formation of lymphoid } \\
\text { nodules with reactive foci } \\
\text { Numerous eosinophils } \\
\text { Obliterative phlebitis } \\
\text { IgG4+ plasmacytes, } \\
\text { postoperative serum } \\
\text { IgG4 } 193 \mathrm{mg} / \mathrm{dL}\end{array}$ & Elevated & 50 & $\begin{array}{l}\text { Henoch- } \\
\text { Schonlein } \\
\text { purpura }\end{array}$ & DG & No data \\
\hline $\begin{array}{l}\text { 3. } 44 / \\
\text { female [5] }\end{array}$ & Asymptomatic & Body & $\begin{array}{l}\text { GIST like } \\
\text { tumor }\end{array}$ & 40 & $\begin{array}{l}\text { Dense lymphoplasmocytes } \\
\text { Storiform fibrosis } \\
\text { Transmural fibrosis } \\
\text { Numerous lymphoid follicules } \\
\text { IgG4 and IgG+ with ratio } 0.4\end{array}$ & No data & $>60$ & ITP & TG & No data \\
\hline $\begin{array}{l}\text { 4. } 27 / \\
\text { female [34] }\end{array}$ & Asymptomatic & Fundus & $\begin{array}{l}\text { GIST/NET } \\
\text { like tumor } \\
\text { with surface } \\
\text { ulceration }\end{array}$ & 40 & $\begin{array}{l}\text { Dense lymphoplasmocytes } \\
\text { Storiform pattern } \\
\text { IgG4+/IgG+ ratio } 25.3 \%\end{array}$ & Normal & 102 & ADPKD & WR & $\begin{array}{l}1 \text { year } \\
\text { recurrence free }\end{array}$ \\
\hline
\end{tabular}

TG, total gastrectomy; WR, wedge resection; DG, distal gastrectomy; ESD, endoscopic submucosal dissection; GIST, gastrointestinal stromal tumor; ITP, idiopathic thrombocytopenic purpura; ADPKD, autosomal dominant polycystic kidney disease; NET, neuroendocrine tumor; IgG4-RD, immunoglobulin G4-RD.

elevated IgG4+ plasmacytic levels were determined in all cases; however, serum IgG4+ level was elevated in only 1 patient, and 3 patients with insignificant IgG4 $+/ \mathrm{IgG}+$ ratio $(0.78,0.4,25.3 \%)$, respectively Table 4 .

The majority of gastroesophageal lesions $(66.66 \%)$ in the literature review were removed surgically due to suspected malignancy. In all cases, the diagnosis was established on the basis of clinical appearance, histopathological analysis, and immunohistochemical staining. In most of the cases, the findings were characteristic for IgG4-RD. The mean age of patients was 57 years (range of $27-81$ years), with the majority being male. The majority of patients respond to steroids treatment, particularly postoperative lesions. The follow-up period of the study group ranged from 2 weeks to 143 months. The recurrence-free cases were 22 (56.41\%), except 2 (5.12\%) one expired during follow-up another developed early gastric cancer; however, patients without follow-up data were $15(38.46 \%)$, respectively.

\section{Discussions}

\section{IGG4-Related Esophageal Disease}

IgG4-related esophageal disease is severely uncommon and characterized by dysphagia, odynophagia, and edematous thickening of the esophageal wall, fibrosis, stromal sclerosis, strictures, sloughing esophagitis, or sometimes on imaging, mimics neoplastic disease, and pathologically by tissue infiltration with dense lymphoplasmacytes and IgG4+ plasma cells $[6,11]$. In most isolated cases, increased levels of IgG4+ plasmacytes subsequently normalized following steroid treatment $[1,12]$.

\section{IgG4-Related Esophageal Ulceration and Stricture}

Esophageal ulceration and stricture are very uncommon, however, recently been more frequently reported in the setting of esophageal disorders and IgG4-RD. A study by Obiorah et al. [13] reported 8 patients with IgG4-related esophagitis with strictures who responded well to steroid therapy. However, no other characteristics of infiltration typical for IgG4-RD, particularly fibrosis, stricture, esophageal wall thickening, elevated IgG4/IgG ratio $[13,14]$, spindle cells infiltration, and phlebitis, were observed in immune-histopathological specimens. DumasCampagna et al. [11] reported a patient with severe ulcerative esophagitis that resembled esophagitis dissecans superficialis with a presence of multiple comorbid conditions, in which oral prednisone, infliximab, and immunosuppressant failed to improve the patient symptoms. 
IgG4-Related Esophageal Mass-Like Lesions

Polypoid or mass-like lesions are common findings in IgG-RD involving gastrointestinal tract, which may be mistaken for cancerous lesions. Lopes et al. [7] reported a GIST-like tumor in the distal stomach with significant lymphoplasmacytic infiltration and IgG4+ plasma cells and recurrence free after laparoscopic esophagectomy. Similarly, study by $\mathrm{Oh}$ et al. [1] and Yang et al. [12] reported masses like lesions in the cervical and lower esophagus with numerous lymphoplasmacytic infiltrates and IgG4+ plasma cells that responded well to steroids therapy. Yakirevich et al. [15] reported specimens of tumor immunoenvironment of esophageal adenocarcinoma following chemoradiotherapy which showed dense lymphoplasmacytic infiltrates, increased IgG4+ plasma cells, and higher IgG4/ IgG ratio. The author also stated that increased IgG4+ plasmacytes might be a reliable factor to predict the prognosis in this entity.

Recent studies have also found dense infiltration of lymphoplasmacytes and IgG4+ plasma cells in lamina propria of severe fibrostenotic esophageal lichen planus $[16,17]$ and in the deep lamina proprial fibrosis in eosinophilic esophagitis [18], which suggests food-specific eosinophilic esophagitis is IgG4-associated not an IgE [19]. In addition, a study by Zukerberg et al. [20] revealed intrasquamous IgG4 deposits in 16 of 21 eosinophilic esophagitis cases concluded that intrasquamous IgG4 deposit is a valuable marker in the area of differentiation between eosinophilic esophagitis and gastroesophageal reflux disease.

IgG4-related esophageal disease should be kept in mind in the differential diagnosis of dysphagic patients presenting with esophageal stricture, ulcer, tumor, or unexplained esophagitis with strictures.

\section{IGG4-Related Gastric Disease}

The possible involvement of the gastrointestinal tract with IgG4-RD is known from published studies presenting case reports, case series, and research papers. There is much argument and concerning, however, as to when the diagnosis of IgG4-related disease can be made in case of upper gastrointestinal involvement. Although some of the reported cases are suspected to be not IgG4-RD but mimickers. Moreover, in this study, isolated gastric IgG4-RD, typical gastric IgG4- $R D$, and nontypical gastric IgG4-RD are categorized in details in the form of "nodular lesions," "tumefactive lesions," "ulcerative lesions," "chronic gastritis," and "malignant lesions."

IgG4-Related Gastroesophageal Disease

\section{IgG4-Related Gastric Nodular Lesions}

Gastric nodular lesions are commonly found during esophagogastroduodenoscopy. It is most frequently associated with Helicobacter pylori infection [21], and rarely, gastric nodular lesions are associated with IgG4+ plasmacytes. Baez et al. [22] reported a patient with sialadenitis and AIP, who showed diffusely thickened gastric nodular mucosa with marked IgG4+ counts and elevated serum IgG level. In 1 AIP patient, numerous sporadic polyps with erosion were also observed in the gastric body, presenting with significant counts of IgG4+ plasmacytes [23]. Two patients with fibrotic nodular lesions in gastric fundus and pyloro-antral junction associated Raynaud's disease and autoimmune polyendocrinopathy showed copious IgG4+ plasmacytes [24]. Moreover, $\mathrm{Na}$ et al. [25] reported an endoscopically resected $8 \mathrm{~mm}$ gastric nodular lesion with marked submucosal fibrosis, a storiform pattern, multiple lymphoid follicles, dense lymphoplasmacytic infiltrates, and diffusely scattered IgG4+ plasmacytes within the lesion as well as elevated IgG4/IgG ratio about $80-90 \%$. Recently, 1 patient reported with bilateral submandibular salivary glands swelling and multiple submucosal tumor-like nodules in the stomach, which showed severe storiform fibrosis, abundant IgG4+ counts, and elevated serum IgG/IgG4 levels. The patient showed an excellent response to steroid therapy [26].

The abundance of IgG4+ plasmacytic infiltration is not uncommon in the GI tract in the setting of AIP [27]. IgG4+ plasmacytic infiltration may also occur within gastric mucosa in other situations. Serum IgG4 concentration is increased in patients with associated AIP [28].

\section{IgG4-Related Gastric Tumefactive Lesions}

IgG4-related tumefactive lesion was first reported to be found at various sites in patients with AIP $[29,30]$ including the liver [31], lungs [32], and pituitary gland [33]. In this condition, levels of serum IgG4 significantly increased. Recently, it's been reported frequently in the stomach, a novel site for this inflammatory pseudotumor subtype [30, 34]. IgG4-RDs are often misdiagnosed since the lesions can mimic tumors and might be misinterpreted clinically and radiologically as a neoplasm $[4,35]$.

Eleven case presenting studies with IgG4+ gastric tumefactive lesions were analyzed retrospectively. Four patients had solitary tumefactive mass lesions, presenting with increased IgG4+ plasmacytic counts, storiform pattern, and elevated IgG4/IgG ratio in 1 patient $[28,30,36]$. The 2 patients with IgG4+ gastric tumefactive lesions also had histories of Hashimoto's thyroiditis as well as possible primary biliary cirrhosis and autosomal dominant poly- 
cystic kidney disease, respectively [34, 37]. Besides, 2 patients had gastric antral wall thickening, one with an adjacent ulcer presenting characteristic for IgG4-RD with an association of IgG4-related skin and lung disease [38] and another with an ulcer-infiltrative tumor in the antrum showing a storiform pattern, obliterative phlebitis, and increased postoperative serum IgG4 level [35]. Furthermore, 2 patients had GIST-like pseudotumors in the gastric body and antrum, revealed copious infiltration of IgG4+ plasmacytes $[39,40]$. Inoue et al. [41] observed a solid lesion within the gastric antrum in a patient previously diagnosed with disease involvement of optic neuropathy, dacryoadenitis, periaortitis, retroperitoneal fibrosis, presenting with dense fibrosis, obliterative phlebitis, and increased IgG4+ plasmacytes. Moreover, Seo et al. [5] reported 2 patients, one with gastric cancer and another with a history of idiopathic thrombocytopenic purpura presenting with GIST-like tumors in the gastric body and antrum with abundant IgG and IgG4+ plasmacytes.

Seven of the 11 cases showing a solitary lesion had no sign of multiorgan involvement. Most cases of gastric IgG4+ tumefactive lesions involved the submucosal layer of the stomach. Muscular propria or mucosa was variably involved. All gastric tumefactive lesions were IgG4+, and serum IgG4 was elevated in only 3 patients.

Histologically, inflammatory tumefactive lesions are characterized by an irregular proliferation of myofibroblasts with a surrounding inflammatory cell infiltrates. The IgG4-related inflammatory pseudotumors are characterized by dense infiltration of lymphoplasmacytes, obliterated veins, storiform fibrosis, and IgG4+ plasmacytes. However, the mechanism by which increased IgG4 levels can induce pseudotumor formation is unclear [30, 34].

\section{IgG4-Related Gastric Ulcerative Lesions}

IgG4-related gastric ulcers are very uncommon and by the time these diffuse gastric ulcers make scars, fistula [42], fibrosis, and stricture of the gastric lumen [27, 43]. Gastric involvement [22] of IgG4+ ulcers can be found significantly more frequently in patients with AIP [44]. Fujita et al. [27] reported refractory multiple gastric ulcers that worsened after effective $H$. pylori eradication therapy, and biopsy of the lesions showed increased IgG4+ plasmacytes. In addition, 2 patients, one with intractable gastric ulcer that was suspicious for malignant features after antacids regimen failed to improve the ulcer [43] and another with giant gastric ulceration [12], both lesions showed fibrosis, storiform pattern, and significant counts of IgG4+ plasmacytes. Frydman et al. [42] report- ed a patient with acute gastric-pericardial fistula secondary to an IgG4-related chronic necrotic gastric ulcer. A pathological specimen of complete gastrectomy showed extensive fibrosis with abundant infiltration of IgG4+ plasmacytes. Furthermore, Li et al. [45] reported $H$. $p y$ lori+ dual gastric ulcers with surrounding atrophic tissue and enlarged perigastric lymph nodes. The resected tissue showed submucosal fibrosis, dense lymphoplasmacytes, numerous lymphoid follicles, obliterated veins, and higher counts of IgG4+ plasmacytes.

IgG4-RD is an uncommon but potentially causes chronic gastric ulceration [46], mainly when marked fibrosis and lymphoplasmacytes with lymphoid follicles are present within the ulcer and adjacent tissue [43].

\section{IgG4-RD and Autoimmune Gastritis}

Autoimmune gastritis is a type of atrophic gastritis that is restricted to the gastric body which causes impaired absorption of vitamin B12 due to the immune destruction of parietal cells in the setting of atrophic gastritis, and as a result, pernicious anemia occurs. IgG4-RD seems to be still controversial [47]. In the histopathological analysis, histopathology is not the gold standard for the diagnosis of IgG4-RD. Several papers warn of overemphasizing the histopathological findings, in particular, IgG4 immunostaining. Strehl et al. [48] analyzed tissue samples from patients with nonspecific chronic inflammatory conditions and found that in several inflammatory conditions such as rheumatoid arthritis, oral cavity lesions, and some kinds of skin disease, copious IgG4+ plasmacytes infiltration was seen. Bedeir et al. [49] examined gastric biopsy specimens of 17 patients with a medical history of chronic atrophic gastritis and pernicious anemia which revealed 5 or more IgG4+ plasmacytes/ $\mathrm{HPF}$, and the control group in the study, which was positive for atrophic gastritis and negative for pernicious anemia or $H$. pylori gastritis without pernicious anemia showed no increase in IgG4+ plasmacytes. Besides, patients with pernicious anemia may have increased IgG4+ plasmacytic infiltration in gastric mucosa [25]. Moreover, IgG4+ plasmacytes may play a key role in the pathogenesis of pernicious anemia and can be a useful marker in recognizing a subset of patients with atrophic gastritis who may have pernicious anemia. Uehara et al. [50] reported 13 cases with IgG4-related chronic gastritis and chronic active gastritis-associated AIP. Endoscopic findings of the gastric fundus and pyloric region were remarkable for redness, erosion, atrophy, and thickening of the gastric wall. The IgG4/IgG ratio in the lower lamina propria of the fundic mucosa was significantly higher than 
that in the upper lamina propria in patients with both $H$. pylori+ and negative groups, and IgG4/IgG ratio in the lower lamina propria of the pyloric mucosa was significantly higher than that in the upper lamina propria in steroid negative patients. In contrast, Culver et al. [51], examined gastric biopsy specimens in patients with AIP and chronic active gastritis, which contained lymphocytes, neutrophils, macrophages, and mast cells, without other histological characteristics of IgG4-RD. Furthermore, the author also stated that $H$. pylori plasminogenbinding protein has no role as a microbial antigen in IgG4-RD.

\section{IgG4-RD and Gastric Malignancy}

IgG4-RD was considered to be a benign disease in previous studies. However, recently, IgG4-RD with concomitant malignancies at different anatomical sites has potentiated growing attention of clinician [46, 52]. IgG4-related gastric malignancy is, however, potentially dangerous mimickers and obviously not a disease that belongs in the spectrum of IgG4-RD. Several researchers have documented that peritumoral IgG4+ plasmacytes infiltration is sometimes present in a variety of cancers, which is called IgG4-reaction [53]. According to Yamamoto et al. [54], malignancies are the possible complication in patients with IgG4-RD, such as gastric signet ring cell carcinoma concurrent with morphologically verified IgG4$\mathrm{RD}$ [55]. Smoking history has found to be a risk factor for IgG4-related concomitant malignancy [56].

Whether IgG4-RD can increase the risk of malignancy remains controversial [10]. Speculation exists that IgG4$\mathrm{RD}$ and AIP represent a premalignant state or paraneoplastic condition [57]. However, no vigorous study has proven these hypotheses $[57,58]$. Serum IgG4 levels at the diagnosis of AIP are significantly higher in AIP patients with cancer than in those without cancer [57]. An active IgG4-RD state is supposed to be a strong risk factor for malignancy formation, particularly during the first year after the diagnosis of IgG4-RD [56, 59]. Hirano et al. [60] examined 2 patients with IgG4-related AIP on steroid therapy prior to gastric cancer development. In these patients, the earlier episode of the gastric cancer was counted. Li et al. [61] reported an H. pylori+ IgG4-related AIP, as well as $H$. pylori+ early moderately differentiated adenocarcinoma of gastric pylorus with dense lymphoplasmacytes, elevated serum IgG4, and patchy distribution of IgG4+ plasmacytes in the cancer stroma. Inoue et al. [62] reported a patient with a long history of sclerosing cholangitis presented with adenocarcinoma of the gastric antrum, bile duct, pancreas, and kidney lesions. The resect-

IgG4-Related Gastroesophageal Disease ed tissue revealed dense lymphoplasmacytic infiltrates with lymph follicles, increased IgG4+ plasmacytes, and elevated IgG4/IgG ratio: $81.5 \%$. However, typical storiform fibrosis and obliterative phlebitis, which are characteristic histological findings of IgG4-RD, were not noticed. Horita et al. [63] reported a patient with IgG4-related submandibular gland, lymph node, lung, kidney, aortic wall, and prostate lesions with concomitant gastric cancer. The distal gastrectomy showed significant IgG4+ plasmacytes and high serum IgG and IgG4 level. This suggests that the stomach can also be a site of involvement of IgG4-RD. Although a study by Shiokawa et al. [57] showed 2 patients with gastric cancer and IgG4-RD who had many IgG4+ plasmacytes infiltrates around the tumor cells, they do not consider the stomach to be one of the affected organs of IgG4-RD in these patients .

Moreover, malignancies as complications to IgG4-RD are categorized as lymphoma and nonlymphoid tumors. Lymphoma presents a background of chronic inflammation and includes mucosa-associated lymphoid tissue lymphoma and non-Hodgkin lymphoma [54, 63]. The overall incidence of malignancy in patients with IgG4-RD is 23 times higher than that in the general population [64]. Lymphadenopathy commonly exists in IgG4-RD; it can appear before, concurrent with, or after the diagnosis of this disease, which is characterized by tumefactive lesions mainly affecting extranodal sites [65]. According to Ahn et al. [64], lymphoma is the most common malignancy associated with IgG4-RD. The risk and incidence of malignancy in patients with non-Hodgkin lymphoma are severely high for all periods of diagnosis of IgG4-RD [64]. Moreover, long-term chemotherapy for B cell lymphoma may cause IgG4-RD [66].

\section{Diagnostic Criteria}

The diagnostic guideline for IgG4-RD and IgG4-related other organ involvement is complex and usually requires a combination of clinicopathological correlation, imaging, and serological analyses [46]. Difficult preoperative diagnosis of gastroesophageal IgG4-RD may require a full thickness biopsy and review biopsy samples that obtained earlier to prevent unwarranted surgeries. IgG4RDs are often misdiagnosed; any undiagnosed mass concerning symptoms should be verified with the biopsy; however, tissue diagnosis is still mandatory. The IgG4 levels alone are actually not as beneficial as its elevation observed in the list of other diseases. Moreover, magnetic resonance imaging and fluorodeoxyglucose-positron emission tomography have shown usefulness for detecting multiorgan involvement $[47,63,67]$. Based on the con- 


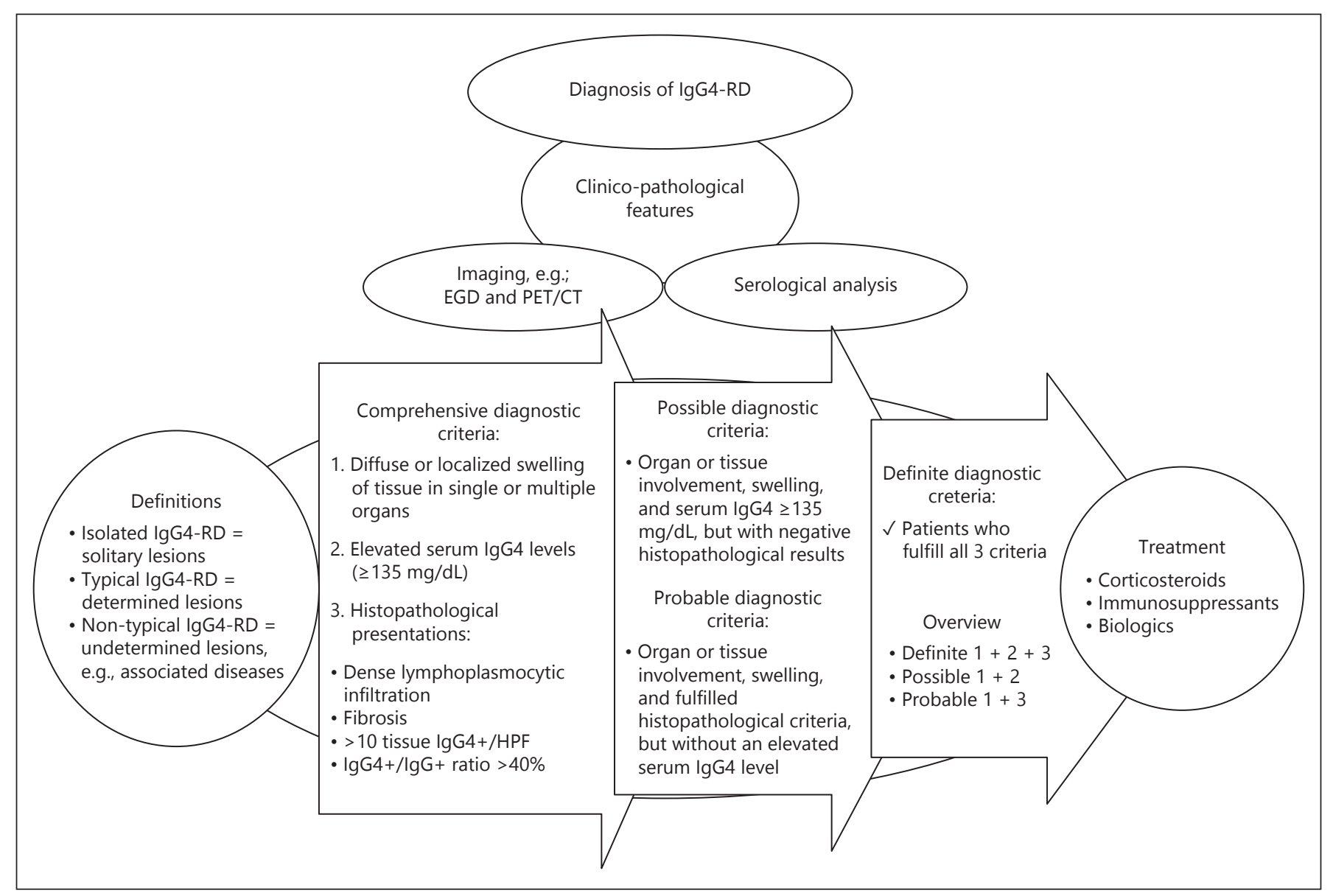

Fig. 1. IgG4-related disease diagnostic criteria. IgG4-RD, immunoglobulin G4-related disease; EGD, esophagogastroduodenoscopy.

sensus statement [68], 4 minimal criteria were proposed for IgG4-RD involvements of new organs: (1) characteristic histologic findings (particularly storiform fibrosis and obliterative phlebitis), increased IgG4+ plasmacytes and IgG4/IgG+ ratio; (2) high serum IgG4 level; (3) an effective response to corticosteroid; (4) coexistence of other organ involvements with IgG4-RD. A definite diagnosis of IgG4$\mathrm{RD}$ can be made by a combination of comprehensive diagnostic criteria and organ-specific criteria - Possible diagnostic criteria and Probable diagnostic criteria [69] (Fig. 1). However, these criteria did not include the concept of IgG4-RD restricted to the gastrointestinal tract.

\section{Treatment}

The treatment approaches for gastroesophageal involvements of IgG4-RD are either medicinal or surgical. Thus, appropriate treatment strategies for gastroesophageal IgG4-RD are mandatory by the physicians, especially gastroenterologists.
In 2015, International Consensus Guidelines for therapeutic purposes of IgG4-RD was published. The first-line treatment strategy for IgG4-RD management consists of corticosteroids administration. If persistently active disease other immunosuppressants such as azathioprine or mycophenolate mofetil may be administered [70]. The effect of corticosteroids is so overwhelming that it is has been suggested as one diagnostic criterion for the disease [4]. However, patients with mild disease or without the involvement of significant organs may remain under observation. Biologics, such as rituximab, may be an appropriate choice for patients contraindicated with corticosteroids [70]. Besides, biologics are effective for the relapses of IgG4-RD [47].

However, due to solid lesions and ulcerations raising suspicions of malignant conditions, the majority of patients underwent surgery. High-incidence of IgG4-RD manifested by inflammatory tumors was observed in the review, awareness of doctors should be raised to avoid unnecessary surgical treatment $[25,30,34]$. 
In relation to most of the gastroesophageal lesions, cases of patients were reported with esophageal ulceration and stricture, gastric mucosal ulceration, inflammatory pseudotumors, and gastroesophageal wall thickening developing in the course of IgG4-RD and respond excellently to corticosteroids treatment.

In this aspect, however, further studies are required.

A careful observation of patients over time is also required because the characteristics of IgG4-RD may develop further lesions in other organs in later years $[2,3]$.

\section{Conclusions}

IgG4-RD is a recently recognized clinical entity characterized by inflammatory and fibrotic courses. IgG4$\mathrm{RD}$ with gastroesophageal involvement may be manifested by isolated, typical, and nontypical lesions; however; some lesions are suspected to be not IgG4-RD but mimickers and should be taken into consideration in differential diagnosis. Making an ultimate diagnosis without clinicopathological and serological examination appears to be difficult and can lead to misdiagnosis. Moreover, deep mucosal biopsy and evaluation of previously obtained biopsy samples are crucial to avoid inappropriate treatment. IgG4-RD responds well to steroid therapy and suggested as one diagnostic criterion for the disease. However, on this matter, further studies are required.

\section{Acknowledgment}

Not applicable.

\section{Statement of Ethics}

The authors have no ethical conflicts to disclose.

\section{Disclosure Statement}

The authors report no conflicts of interest to declare.

\section{Funding Source}

This study was supported by Science and Technology Program of Tianjin (15ZXJZSY00020) and Natural Science Foundation of Tianjin (18JCZDJC45200).

\section{Author Contributions}

All the persons who have made substantial contributions to the work reported in the manuscript, their names declared in the author list. The author S.K.: contributed to the paper in writing, data collection, data analysis, and manuscript preparation." L.P.Z., K.J., and W.L.: contributed in literature search and in the definition of intellectual content. X.C. and B.M.W.: contributed to the study concept, design, manuscript editing, and manuscript review. All authors read and approved the final manuscript.

\section{References}

1 Oh JH, Lee TH, Kim HS, Jung CS, Lee JS, Hong SJ, et al. Esophageal Involvement of Immunoglobulin G4-Related Disease: A Case Report and Literature Review. Medicine (Baltimore). 2015 Dec;94(50):e2122.

2 Stone JH, Zen Y, Deshpande V. IgG4-related disease. N Engl J Med. 2012 Feb;366(6):539_ 51.

3 Skorus U, Kenig J, Mastalerz K. IgG4-related disease manifesting as an isolated gastric lesion- a literature review. Pol Przegl Chir. 2018 Jun;90(4):41-5.

4 Nambiar S, Oliver TI. IgG4 Related Disease (IgG4-RD). StatPearls. Treasure Island (FL): StatPearls Publishing LLC; 2018.

5 Seo HS, Jung YJ, Park CH, Song KY, Jung ES. IgG4-related Disease in the Stomach which Was Confused with Gastrointestinal Stromal Tumor (GIST): Two Case Reports and Review of the Literature. J Gastric Cancer. 2018 Mar; 18(1):99-107.

6 Lee H, Joo M, Song TJ, Chang SH, Kim H, Kim YS, et al. IgG4-related sclerosing esopha- gitis: a case report. Gastrointest Endosc. 2011 Apr;73(4):834-7.

7 Lopes J, Hochwald SN, Lancia N, Dixon LR, Ben-David K. Autoimmune esophagitis: IgG4-related tumors of the esophagus. J Gastrointest Surg. 2010 Jun;14(6):1031-4.

8 Deshpande V. IgG4-Related Disease of the Gastrointestinal Tract: A 21st Century Chameleon. Arch Pathol Lab Med. 2015 Jun; 139(6):742-9.

9 Lang D, Zwerina J, Pieringer H. IgG4-related disease: current challenges and future prospects. Ther Clin Risk Manag. 2016 Feb;12: 189-99.

10 Inoue D, Yoshida K, Yoneda N, Ozaki K, Matsubara T, Nagai K, et al. IgG4-related disease: dataset of 235 consecutive patients. Medicine (Baltimore). 2015 Apr;94(15):e680.

11 Dumas-Campagna M, Bouchard S, Soucy G, Bouin M. IgG4-Related Esophageal Disease Presenting as Esophagitis Dissecans Superficialis With Chronic Strictures. J Clin Med Res. 2014 Aug;6(4):295-8.
12 Yang L, Jin P, Sheng JQ. Immunoglobulin G4related disease (IgG4-RD) affecting the esophagus, stomach, and liver. Endoscopy. 2015;47(suppl 1 UCTN):E96-7.

13 Obiorah I, Hussain A, Palese C, Azumi N, Benjamin S, Ozdemirli M. IgG4-related disease involving the esophagus: a clinicopathological study. Dis Esophagus. 2017 Dec; 30(12): $1-7$

14 Mori S, Tahashi Y, Uchida K, Ikeura T, Danbara N, Wakamatsu T, et al. Sclerosing Esophagitis with IgG4-positive Plasma Cell Infiltration. Intern Med. 2017 Nov;56(22):3023-6.

15 Yakirevich E, Lu S, Allen D, Mangray S, Fanion JR, Lombardo KA, et al. Prognostic significance of IgG4+ plasma cell infiltrates following neoadjuvant chemoradiation therapy for esophageal adenocarcinoma. Hum Pathol. 2017 Aug;66:126-35.

16 Podboy AJ, Alexander JA, Smyrk TC, Halland M, Ravi K, Geno DM, et al. Occurrence of IgG4 in Esophageal Lichen Planus. Clin Gastroenterol Hepatol. 2017 Dec;15(12):1975-7. 
17 Podboy AJ, Mara K, Smyrk T, Alexander JA, Geno DM, Halland M, et al. Severe Fibrostenotic Esophageal Lichen Planus in Adults is Associated with the Presence of IGG4 on Esophageal Biopsies. Gastroenterology. 2017; 152(5):S995.

18 Clayton F, Fang JC, Gleich GJ, Lucendo AJ, Olalla JM, Vinson LA, et al. Eosinophilic esophagitis in adults is associated with IgG4 and not mediated by IgE. Gastroenterology. 2014 Sep;147(3):602-9.

19 Wright BL, Kulis M, Guo R, Orgel KA, Wolf WA, Burks AW, et al. Food-specific IgG4 is associated with eosinophilic esophagitis. J Allergy Clin Immunol. 2016 Oct;138(4):11901192.e3.

20 Zukerberg L, Mahadevan K, Selig M, Deshpande V. Oesophageal intrasquamous IgG4 deposits: an adjunctive marker to distinguish eosinophilic oesophagitis from reflux oesophagitis. Histopathology. 2016 Jun;68(7): 968-76.

21 Kim JW, Lee SY, Kim JH, Sung IK, Park HS, Shim CS, et al. Nodule Regression in Adults With Nodular Gastritis. Gastroenterol Res. 2015 Dec;8(6):296-302.

22 Baez JC, Hamilton MJ, Bellizzi A, Mortele KJ. Gastric involvement in autoimmune pancreatitis: MDCT and histopathologic features. JOP. 2010 Nov; 11(6):610-3.

23 Kaji R, Okabe Y, Ishida Y, Takedatsu H, Kawahara A, Aino H, et al. Autoimmune pancreatitis presenting with IgG4-positive multiple gastric polyps. Gastrointest Endosc. 2010 Feb;71(2):420-2.

24 Chetty R, Serra S, Gauchotte G, Märkl B, Agaimy A. Sclerosing nodular lesions of the gastrointestinal tract containing large numbers of IgG4 plasma cells. Pathology. 2011 Jan; 43(1):31-5.

25 Na KY, Sung JY, Jang JY, Lim SJ, Kim GY, Kim YW, et al. Gastric nodular lesion caused by IgG4-related disease. Pathol Int. 2012 Oct; 62(10):716-8

26 Mine S, Ozawa E, Ohnita K, Abe K, Nakao K. A case of IgG4-related disease presenting with multiple gastric submucosal tumors. Gastrointest Endosc. 2018 Feb;87(2):608-10.

27 Fujita T, Ando T, Sakakibara M, Hosoda W, Goto $\mathrm{H}$. Refractory gastric ulcer with abundant IgG4-positive plasma cell infiltration: a case report. World J Gastroenterol. 2010 May; 16(17):2183-6.

28 Woo CG, Yook JH, Kim AY, Kim J. IgG4-Related Disease Presented as a Mural Mass in the Stomach. J Pathol Transl Med. 2016 Jan; 50(1):67-70.

29 Zen Y, Harada K, Sasaki M, Sato Y, Tsuneyama K, Haratake J, et al. IgG4-related sclerosing cholangitis with and without hepatic inflammatory pseudotumor, and sclerosing pancreatitis-associated sclerosing cholangitis: do they belong to a spectrum of sclerosing pancreatitis? Am J Surg Pathol. 2004 Sep; 28(9):1193-203.

30 Rollins KE, Mehta SP, O’Donovan M, Safranek PM. Gastric IgG4-Related Autoimmune Fi- brosclerosing Pseudotumour: A Novel Location. ISRN Gastroenterol. 2011;2011:873087.

31 Uchida K, Satoi S, Miyoshi H, Hachimine D, Ikeura T, Shimatani M, et al. Inflammatory pseudotumors of the pancreas and liver with infiltration of IgG4-positive plasma cells. In tern Med. 2007;46(17):1409-12.

32 Zen Y, Kitagawa S, Minato H, Kurumaya H, Katayanagi K, Masuda S, et al. IgG4-positive plasma cells in inflammatory pseudotumor (plasma cell granuloma) of the lung. Hum Pathol. 2005 Jul;36(7):710-7.

33 Wong S, Lam WY, Wong WK, Lee KC. Hypophysitis presented as inflammatory pseudotumor in immunoglobulin G4-related systemic disease. Hum Pathol. 2007 Nov;38(11):1720-3.

34 Cheong HR, Lee BE, Song GA, Kim GH, An SG, Lim W. Immunoglobulin G4-Related Inflammatory Pseudotumor Presenting as a Solitary Mass in the Stomach. Clin Endosc. 2016 Mar;49(2):197-201.

35 Bulanov D, Arabadzhieva E, Bonev S, Yonkov A, Kyoseva D, Dikov T, et al. A rare case of IgG4-related disease: a gastric mass, associated with regional lymphadenopathy. BMC Surg. 2016 Jun;16(1):37.

36 Kim DH, Kim J, Park DH, Lee JH, Choi KD, Lee GH, et al. Immunoglobulin G4-related inflammatory pseudotumor of the stomach. Gastrointest Endosc. 2012 Aug;76(2):451-2.

37 Zhang H, Jin Z, Ding S. Gastric calcifying fibrous tumor: A case of suspected immunoglobulin G4-related gastric disease. Saudi J Gastroenterol. 2015 Nov-Dec;21(6):423-6.

38 Kawano H, Ishii A, Kimura T, Takahashi T, Hironaka H, Kawano M, et al. IgG4-related disease manifesting the gastric wall thickening. Pathol Int. 2016 Jan;66(1):23-8.

39 Otsuka R, Kano M, Hayashi H, Hanari N, Gunji H, Hayano K, et al. Probable IgG4-related sclerosing disease presenting as a gastric submucosal tumor with an intense tracer uptake on PET/CT: a case report. Surg Case Rep. 2016 Dec;2(1):33.

40 Bohlok A, Khoury ME, Tulelli B, Verset L, Zaarour A, Demetter P, et al. A rare presentation of IgG4 related disease as a gastric antral lesion: case report and review of the literature. Int J Surg Case Rep. 2018;51:244-7.

41 Inoue D, Yoneda N, Yoshida K, Nuka H, Kinoshita J, Fushida S, et al. Imaging and pathological features of gastric lesion of immunoglobulin G4-related disease: A case report and review of the recent literature. Mod Rheumatol. 2019 Mar;29(2):377-382.

42 Frydman J, Grunner S, Kluger Y. IgG4-related disease manifesting as an acute gastric-pericardial fistula. World J Gastroenterol. 2014 Nov;20(44):16782-5.

43 Bateman AC, Sommerlad M, Underwood TJ. Chronic gastric ulceration: a novel manifestation of IgG4-related disease? J Clin Pathol. 2012 Jun;65(6):569-70.

44 Shinji A, Sano K, Hamano H, Unno H, Fukushima M, Nakamura N, et al. Autoimmune pancreatitis is closely associated with gastric ulcer presenting with abundant IgG4-bearing plasma cell infiltration. Gastrointest Endosc. 2004 Apr;59(4):506-11.

45 Li X, Zheng S, Xiao L, Shen D, Ji D. Gastric ulcer caused by immunoglobulin G4-related diseases: A case report. Case Rep Intern Med. 2015;2(3):35.

46 Notohara K, Kamisawa T, Uchida K, Zen Y, Kawano M, Kasashima S, et al. Gastrointestinal manifestation of immunoglobulin G4-related disease: clarification through a multicenter survey. J Gastroenterol. 2018 Jul;53(7):845-53.

47 Legatowicz-Koprowska M. IgG4-related disease: why is it so important? Cent Eur J Immunol. 2018;43(2):204-8.

48 Strehl JD, Hartmann A, Agaimy A. Numerous IgG4-positive plasma cells are ubiquitous in diverse localised non-specific chronic inflammatory conditions and need to be distinguished from IgG4-related systemic disorders. J Clin Pathol. 2011 Mar;64(3):237-43.

49 Bedeir AS, Lash RH, Lash JG, Ray MB. Significant increase in IgG4+ plasma cells in gastric biopsy specimens from patients with pernicious anaemia. J Clin Pathol. 2010 Nov; 63(11):999-1001.

50 Uehara T, Hamano H, Kawa S, Sano K, Oki K, Kobayashi $\mathrm{Y}$, et al. Chronic gastritis in the setting of autoimmune pancreatitis. Am J Surg Pathol. 2010 Sep;34(9):1241-9.

51 Culver EL, Smit WL, Evans C, Sadler R, Cargill T, Makuch M, et al. No evidence to support a role for Helicobacter pylori infection and plasminogen binding protein in autoimmune pancreatitis and IgG4-related disease in a UK cohort. Pancreatology. 2017 May-Jun; 17(3):395-402.

52 Senba Y, Mise K, Sumida K, Hayami N, Suwabe T, Ubara Y, et al. IgG4-Related Disease and Malignant Tumor. In: Umehara H, Okazaki K, Stone JH, Kawa S, Kawano M, editors. IgG4-Related Disease. Tokyo: Springer Japan; 2014. pp. 219-24.

53 Harada K, Shimoda S, Kimura Y, Sato Y, Ikeda $\mathrm{H}$, Igarashi S, et al. Significance of immunoglobulin G4 (IgG4)-positive cells in extrahepatic cholangiocarcinoma: molecular mechanism of IgG4 reaction in cancer tissue. Hepatology. 2012 Jul;56(1):157-64.

54 Yamamoto M, Takahashi H, Tabeya T, Suzuki C, Naishiro Y, Ishigami K, et al. Risk of malignancies in IgG4-related disease. Mod Rheumatol. 2012 Jun;22(3):414-8.

55 Kazantseva IA, Lishchuk SV, Gribunov YP, Shestakova IN, Pavlov KA. [Gastric cancer concurrent with IgG4-related disease: A clinical case and a review of literature]. Arkh Patol. 2016 Jul-Aug;78(4):43-7.

56 Feng YL, Wu D, Zhang SY, Wu X, Shu HJ, Yang AM, et al. [A retrospective case-control study of immunoglobulin G4-related disease combined with malignancy]. Zhonghua Nei Ke Za Zhi. 2016 Nov;55(11):869-71.

57 Shiokawa M, Kodama Y, Yoshimura K, Kawanami C, Mimura J, Yamashita Y, et al. Risk of cancer in patients with autoimmune pancreatitis. Am J Gastroenterol. 2013 Apr; 108(4):610-7. 
58 Wallace ZS, Wallace CJ, Lu N, Choi HK, Stone JH. Association of IgG4-Related Disease With History of Malignancy. Arthritis Rheumatol. 2016 Sep;68(9):2283-9.

59 Asano J, Watanabe T, Oguchi T, Kanai $\mathrm{K}$, Maruyama M, Ito T, et al. Association Between Immunoglobulin G4-related Disease and Malignancy within 12 Years after Diagnosis: An Analysis after Longterm Followup. J Rheumatol. 2015 Nov;42(11):2135-42.

60 Hirano K, Tada M, Sasahira N, Isayama H, Mizuno S, Takagi K, et al. Incidence of malignancies in patients with IgG4-related disease. Intern Med. 2014;53(3):171-6.

61 Li M, Zhou Q, Yang K, Brigstock DR, Zhang L, Xiu M, et al. Rare case of Helicobacter pylori-positive multiorgan IgG4-related disease and gastric cancer. World J Gastroenterol. 2015 Mar;21(11):3429-34.

62 Inoue K, Okubo T, Kato T, Shimamura K, Sugita T, Kubota M, et al. IgG4-related stomach muscle lesion with a renal pseudotumor and multiple renal rim-like lesions: A rare manifestation of IgG4-related disease. Mod Rheumatol. 2018 Jan;28(1):188-92.
63 Horita S, Fujii H, Mizushima I, Fujisawa Y, Hara S, Yamada K, et al. A case of IgG4-related tubulointerstitial nephritis and membranous glomerulonephritis during the clinical course of gastric cancer: imaging features of IgG4-related kidney disease. Mod Rheumatol. 2019 May;29(3):542-6.

64 Ahn SS, Song JJ, Park YB, Lee SW. Malignancies in Korean patients with immunoglobulin G4-related disease. Int J Rheum Dis. 2017 Aug;20(8):1028-35.

65 Cheuk W, Chan JK. Lymphadenopathy of IgG4-related disease: an underdiagnosed and overdiagnosed entity. Semin Diagn Pathol. 2012 Nov;29(4):226-34.

66 Mitsui T, Yokohama A, Koiso H, Ishizaki T, Uchiumi H, Saitoh T, et al. Development of IgG4-related disease 10 years after chemotherapy for diffuse large B cell lymphoma and longstanding bronchial asthma. Int J Hematol. 2013 Jul;98(1):122-8.
67 Ebbo M, Grados A, Guedj E, Gobert D, Colavolpe C, Zaidan M, et al. Usefulness of 2-[18F]fluoro-2-deoxy-D-glucose-positron emission tomography/computed tomography for staging and evaluation of treatment response in IgG4-related disease: a retrospective multicenter study. Arthritis Care Res (Hoboken). 2014 Jan;66(1):86-96.

68 Deshpande V, Zen Y, Chan JK, Yi EE, Sato Y, Yoshino T, et al. Consensus statement on the pathology of IgG4-related disease. Mod Pathol. 2012 Sep;25(9):1181-92.

69 Umehara H, Okazaki K, Masaki Y, Kawano M, Yamamoto M, Saeki T, et al. Comprehensive diagnostic criteria for IgG4-related disease (IgG4-RD), 2011. Mod Rheumatol. 2012 Feb;22(1):21-30.

70 Khosroshahi A, Wallace ZS, Crowe JL, Akamizu T, Azumi A, Carruthers MN, et al.; Second International Symposium on IgG4Related Disease. International Consensus Guidance Statement on the Management and Treatment of IgG4-Related Disease. Arthritis Rheumatol. 2015 Jul;67(7):168899. 